\title{
Nutrition in Multiple Sclerosis: An integrative review of scientific publications from the last 5 years
}

\section{Nutrición en la Esclerosis Múltiple: Revisión integrativa de las publicaciones científicas en los últimos 5 años}

\begin{abstract}
This study analyzed the profile of scientific production related to the nutritional aspects of the etiology and/or progress of Multiple Sclerosis (MS). We conducted an integrative review that analyzed 64 works published in English, Spanish or Portuguese between 2012 and 2017 on the relationship between nutrition and MS. There was a predominance of studies in humans $(54.0 \%, n=34)$ and randomized clinical trials $(38.3 \%, n=13)$. The association between vitamin $D$ and etiology progression and/or development of disabilities resulting from MS was the most studied aspect $(30.2 \%$, $n=19)$, followed by studies that evaluated the importance of fat concentration and/or types for MS risk $(22.2 \%, n=$ 14), and research that analyzed the role of antioxidant vitamins $(19.0 \% ; n=12)$ in the disease development and/ or evolution. The study showed that most research involves small samples and that a healthy diet contributes to the prevention and mitigation of disease evolution. However, this affirmation cannot be made with regards to dietary supplements. Further research is necessary, from crosssectional studies to randomized clinical trials considering the wide knowledge gap on this subject.
\end{abstract}

Keywords: Disease progression, Etiology, Multiple sclerosis, Nutrients, Nutrition.

\section{RESUMEN}

El presente estudio buscó plantear el perfil de las producciones científicas que relacionan aspectos nutricionales con la etiología y/o progresión de la Esclerosis Múltiple (EM). Fue una revisión integrativa que analizó 63 trabajos publicados en el idioma inglés, español y portugués, entre 2012 a 2017, sobre la relación entre los aspectos nutricionales y la EM. Predominaron estudios con seres humanos $(54,0 \%$, $n=34)$, del tipo ensayo clínico randomizado $(38,3 \%, n=$ 13). La asociación de la vitamina $D$ con la etiología, progresión y/o desarrollo de incapacidades consecuentes de la EM fue la más estudiada $(30,2 \%, n=19)$, seguida de los estudios que evaluaron la importancia de la concentración y/o de los tipos de gordura para el riesgo o progresión de la $\operatorname{EM}(22,2 \%, n=14)$, y de estudios que analizaron el papel de las vitaminas antioxidantes $(19,0 \% ; n=12)$ en el
Bruna Yhang da Costa Silva', Helena Alves de Carvalho Sampaio', José Artur Costa D'Almeida², Maria Luisa Pereira de Melo ${ }^{3}$.

1. Post-graduate Program in Collective Health - Ceará State University. Fortaleza, Brazil. 2. Neurology Outpatient Service, Fortaleza General Hospital. Fortaleza, Brazil. 3. Masters in Health and Nutrition, Ceará State University. Fortaleza, Brazil.

Corresponding Author: Bruna Yhang da Costa Silva 1145 Estevão Remígio St, Limoeiro do Norte, CE, Brazil; Phone: 55-85-34012290 E-mail: brunayhang@gmail.com

Este trabajo fue recibido el 08 noviermbre de 2017. Aceptado con modificaciones: 14 septiembre de 2018. Aceptado para ser publicado: 26 de noviembre de 2018.

desencadenamiento y/o evolución de la enfermedad. La mayoría de los estudios incluyó muestras pequeñas y una dieta saludable que aporta con la prevención y atenuación de la evolución de la enfermedad. No se pueó hacer esta afirmación para los suplementos dietéticos. Son necesarios más estudios, dada la enorme laguna de conocimiento que envuelve el tema.

Palabras clave: Esclerosis múltiple, Etiología, Nutrición, Nutrientes, Progresión de la enfermedad.

\section{INTRODUCTION}

Multiple Sclerosis (MS) is an autoimmune disease of the Central Nervous System (CNS). It is a chronic, demyelinating 
inflammatory condition and is one of the main causes of disability in young adults'. Predisposition originates in genes linked to the immune system, with the HLA-DRB1*1501 gene being the main risk factor for the disease. However, the development of MS depends on a complex interaction between genetic and environmental factors ${ }^{2}$.

The prevalence of MS has been growing in recent years. In 2008 there were 2.1 million cases worldwide and in 2013, the last published epidemiologic data reached 2.3 million people. It is more common among females, attacking two women for every one $\operatorname{man}^{3}$.

MS is, in general, a high-cost disease and the more diverse the symptoms and the disability level, the more adverse the impact on quality of life of affected individuals and the bigger its financial consequences ${ }^{4}$.

The disease progression, which is typified by a large amount of neurological damage, can be succinctly explained by the accumulation of inflammatory cells in demyelinating lesions, excessive production of reactive oxygen species (ROS) by these cells, phagocytosis induction and myelin lesion by macrophages, besides oligodendrocyte damage and neuronal and axonal injury'.

Some clinical and experimental studies have suggested that specific dietary models may directly slow MS progression or improve the effectiveness of conventional medical therapy ${ }^{5}$. Others have evaluated and detected the influence of certain dietary components on serum levels of pro-inflammatory cytokines and free radical triggers ${ }^{1}$.

Prior studies refer to the impossibility of reaching definite conclusions on the relation between diet and $\mathrm{MS}^{6}$. It is therefore necessary that further research analyze this relationship in detail. Medication treatment is costly ${ }^{7}$, thus, adequate nutrition may be a possible strategy to reduce the financial impact of the disease.

Therefore, aware of the need and importance of research in this area, we performed a complete review seeking to analyze the profile of scientific production related to nutrition, etiology and/or progression of MS.

This article will contribute to the discussion of proper nutrition for patients with MS and other neuro-degenerative disorders, a field in which there is still much controversy and many gaps in knowledge.

\section{MATERIAL AND METHODS}

We conducted an integrative review that analyzed works published on the intersection between "Nutrition and Multiple Sclerosis" and "Nutrients and Multiple Sclerosis". For the obtainment of articles to be analyzed, a search in the Capes Portal was carried out. Capes Portal is a Brazilian metasearch engine containing more than 38 thousand journals available in full text and 130-reference databases ${ }^{8}$. For keywords, we used the terms "nutrition and multiple sclerosis" and "nutrients and multiple sclerosis" in English. Complete texts published in English, Spanish and Portuguese during the last five years were included (from January 2012 to May 2017). The search resulted in 355 articles. Authors read each abstract to identify the general perspective of these publications. Only $64(17.7 \%)$ specifically studied the relationship between MS and nutrition. We proceeded to capture their entire texts for analysis. Table 1 shows the research classification according to a specific dietary component or nutritional pattern related to MS etiology or progression (Table 1).

\section{RESULTS}

Through the analysis of the 64 articles published between January 2012 and May 2017, we perceived that the number of works that directly or indirectly relate to dietary components and/or the development and progress of MS is limited. Among selected studies, 34 (54.0\%) were performed with humans, out of which six $(17.7 \%)$ were cross-sectional studies involving only MS patients; 12 (35.3\%) were casecontrol studies; 13 (38.3\%) were randomized clinical studies; $1(2.9 \%)$ was a cohort study; 1 corresponded to a series of cases $(2.9 \%)$ and the last one $(2.9 \%)$ was a qualitative study that used focus groups and individual interviews as a data collection technique.

The number of individuals with MS (n) that constituted the samples of these studies varied from 5 to 2,469. Excluding three $\mathrm{n}$ extreme values, the mean number of participants was $85.8 \pm 83$.3. The other research found was experimental, involving animals $(n=4 ; 6.3 \%)$ and review studies or systematic reviews ( $\mathrm{n}=25 ; 39.7 \%)$.

The relationship between vitamin D and MS was the most frequently studied, present in $30.2 \%(n=19)$ of articles, being inserted in the research on the association of vitamin D serum levels and/or the etiology, progression and/or development of disabilities resulting from MS.

A total of 14 articles (22.2\%) evaluated the importance of oil concentration and/or specific oil type, such as animal fat, polyunsaturated, isolated or non-isolated fatty acids, saturated fat, $\alpha$-lipoic acid, fish and primrose oil, as well as hemp seed oil and other, as part of the diet or as a supplement, as determinants for MS risk or progression, immunomodulators, CNS lesion triggers, biochemical markers, disability levels, fatigue and attack rate predictors.

There was also a predominance of studies $(19.0 \%$; $n=12)$ that assessed the role of antioxidant vitamins $(A, C$ and/or $\mathrm{E}$ ) in the development and/or evolution of $\mathrm{MS}^{9-20}$ and the influence of some natural bioactive compounds, flavonoids and non-flavonoids with antioxidant and/or anti-inflammatory power $(12.7 \%, \mathrm{n}=8)$, in the disease development, in particular in demyelination ${ }^{21}$ control, and consequently, in the progress of symptoms such as muscular weakness and fatigue ${ }^{22}$.

Repercussions of some dietary models for MS individuals were also assessed $(17.5 \%$ of studies; $n=11)$. Models included were the Paleolithic diet ${ }^{13,23}$, the Mediterranean diet, healthy hypocaloric ${ }^{4,25}$ diets, western hypercaloric ${ }^{26,27}$ diet. Anti-inflamamatory ${ }^{26}$, cold-nature versus hot-nature diet (according to Indian and traditional Chinese medicine) ) $^{28,29,30}$, traditional standard, $\mathrm{DASH}^{24}$, vegetarian ${ }^{31,32}$, lacto-vegetarian 
Table 1. Indexed studies* $(n=64)$ on the influence of nutritional aspects on the etiology and/or progression of MS according to their respective authors.

\begin{tabular}{|c|c|c|c|}
\hline $\begin{array}{l}\text { Dietary component/ } \\
\text { nutritional aspect }\end{array}$ & $\mathbf{N}$ & $\%$ & Authors \\
\hline Vitamin D & 19 & 30.2 & 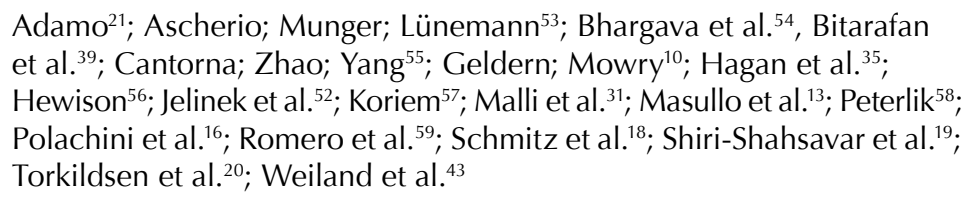 \\
\hline Lipids & 14 & 22.2 & $\begin{array}{l}\text { Adamo }{ }^{21} \text {; Altowaijri; Fryman; Yadav }{ }^{24} \text {; Geldern; Mowry }{ }^{10} ; \text { Haghikia et } \\
\text { al. } .^{63} ; \text { Hoare et al. } .^{22} \text {; Mauriz et al. }{ }^{14} ; \text { Nieto et al. }{ }^{15} \text {; Pantzaris et al. }{ }^{61} ; \text { Rezapour- } \\
\text { Firouzi et al. }{ }^{28} \text {; Rezapour-Firouzi et al. }{ }^{30} \text {; Schmitz et al. }{ }^{18} \text {; Shiri-Shahsavar } \\
\text { et al. } .^{19} \text {; Timmermans et al. }{ }^{60} \text {; Weiland et al. }{ }^{43}\end{array}$ \\
\hline Antioxidant Vitamins & 12 & 19.0 & $\begin{array}{l}\text { Dorosty-Motlagh et al. }{ }^{9} \text {; Geldern; Mowry }{ }^{10} \text {; Honarvar et al. }{ }^{11} \text {; Loken- } \\
\text { Amsrud }{ }^{12} \text {; Masullo et al. }{ }^{13} \text {; Mauriz et al. } .^{14} ; \text { Nieto et al. }{ }^{15} ; \text { Polachini et al. }{ }^{16} \text {; } \\
\text { Saboor-Yaraghi et al. }{ }^{17} ; \text { Schmitz et al. } .^{18} \text {; Shiri-Shahsavar et al. } .^{19} \text {; Torkildsen } \\
\text { et al. }{ }^{20}\end{array}$ \\
\hline Bioactive compounds & 8 & 12.7 & $\begin{array}{l}\text { Adamo }^{21} \text {; Ciftci et al. }{ }^{66} \text {; Geldern; Mowry }{ }^{10} \text {; Mahler et al. }{ }^{22} \text {; Nieto et al. }{ }^{15} \text {; } \\
\text { Riccio; Rossano }{ }^{25} \text {; Solanki et al. }{ }^{65} ; \text { Wu et al. }{ }^{.4}\end{array}$ \\
\hline Dietary Models & 11 & 17.5 & $\begin{array}{l}\text { Altowaijri; Fryman; Yadav }{ }^{24} \text {; Bennett; Bromley'26; Irish }{ }^{23} \text {; Jörg et al. }{ }^{27} \text {; } \\
\text { Malli et al. }{ }^{31} \text {; Masullo et al. }{ }^{13} \text {; Null; Pennesi; Feldman }{ }^{32} \text {; Riccio; Rossano }{ }^{25} \text {; } \\
\text { Rezapour-Firouzi et al. } .^{28} \text {; Rezapour-Firouzi et al. }{ }^{29} \text {; Rezapour-Firouzi } \\
\text { et al. }{ }^{30}\end{array}$ \\
\hline Fiber or probiotics & 7 & 11.1 & $\begin{array}{l}\text { Altowaijri, Fryman; Yadavv24; Bitarafan et al.. }{ }^{39} \text {; Croxford; Miyak }{ }^{69} \text {; Geldern; } \\
\text { Mowry }{ }^{10} \text {; Glenn; Mowry }{ }^{67} \text {; Kouchaki et al. }{ }^{68} \text {; Schmitz et al. }{ }^{18}\end{array}$ \\
\hline Body Adiposity & 7 & 11.1 & $\begin{array}{l}\text { Altowaijri, Fryman e Yadav }{ }^{24} \text {; Coe et al. } .^{33} \text {; Endo; Yokote; Nakayama }{ }^{34} \text {; } \\
\text { Hagan et al. }{ }^{35} \text {; Jelinek et al. }{ }^{36} \text {; Oliveira et al. }{ }^{37} \text {; Wens et al. }{ }^{38} \text {. }\end{array}$ \\
\hline B Complex vitamins & 4 & 6.3 & Adamo ${ }^{21}$; Bitarafan et al..$^{39}$; Masullo et al. ${ }^{13} ;$ Schmitz et al. ${ }^{18}$ \\
\hline Antioxidant minerals & 4 & 6.3 & Bitarafan et al..$^{39}$; Schmitz et al. ${ }^{18}$; Socha et al. ${ }^{40}$; Socha et al. ${ }^{41}$ \\
\hline Others & 15 & 23.8 & 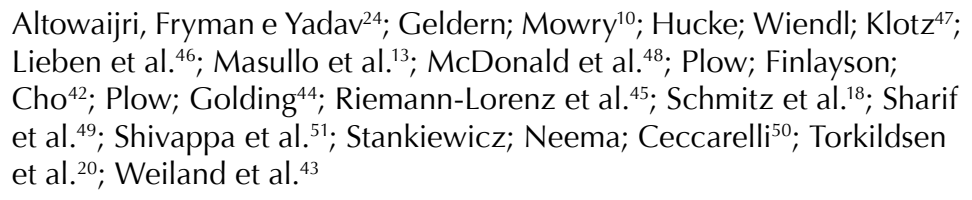 \\
\hline \multicolumn{4}{|c|}{$\begin{array}{l}\text { *Period from January } 2012 \text { to May 2017. The following were considered in "others": food patterns, cow's milk protein and gluten intak } \\
\text { contraindication, importance of educational programs, proteic and uric acid supplementation, salt intake, natural products, vitamir } \\
\text { K, salmon proteoglycans, soy proteases, iron and coffee, dietary inflammatory index and calorie restriction. There were a total of } 10 \\
\text { dietary components/nutritional patterns studied because some studies assessed more than one of these components. }\end{array}$} \\
\hline
\end{tabular}

and animal fat ${ }^{24}$, plus the diet recommended by the National Institute of Health (NIH) Guide to Therapeutic Lifestyle ${ }^{26}$.

Fiber and/or probiotic intake was also a topic approached by some studies $(11.1 \% ; n=7)$ that analyzed the relation between probiotics and disease development, fatigue and intestinal dysbiosis prevention.
There was also research ${ }^{24,33-38}$ on body size, evaluated through Body Mass Index (BMI) and Waist Circumference (WC) and more specifically on adiposity, which could contribute to MS incidence, the appearance of disabilities, development of Metabolic Syndrome and exacerbation of cardiovascular risk in diagnosed individuals. In $6.3 \%(n=4)$ 
of studies, prevalence of vitamin B complex intake (folate, niacin and above all, cobalamin) was found among people diagnosed with this condition ${ }^{13}$, and the relation between these nutrients and etiology and pathology progression was studied ${ }^{18,21,39}$.

In other studies $6.3 \%(n=4)$, the possible action of some minerals with antioxidant potential or their serum levels (zinc, copper, magnesium and mainly selenium) was analyzed, considering diet concentration as determinant for the appereance ${ }^{18,40}$ of MS progression ${ }^{18,40,41}$ and fatigue incidence ${ }^{39}$.

Other nutritional factors were also studied with less frequency, such as food pattern aspects $(3.2 \%$; $n=2)$, intake amounts for different food groups, label reading habits and meal frequency ${ }^{42,43}$, cow milk protein intake contraindication $(1.6 \% ; n=1)$, due to its molecular mimicry with myelin sheath or gluten auto-antigens $\mathrm{s}^{10}(1.6 \% ; n=1)$. Also, the risk of developing celiac disease ${ }^{10}$, benefits of individual or group educational programs $(3.2 \% ; \mathrm{n}=2)$ interference in $\mathrm{MS}^{44,45}$ risk and clinical development, protein supplementation $(1.6 \% ; n=1)$ for the improvement of the cognitive function in patients with this condition ${ }^{46}$, as well as the influence of excessive salt intake $(3.2 \% ; n=2)$ in $M S^{47,48}$.

Finally, as nutritional factors specifically studied we highlight $(1.6 \% ; n=1)$, the inclusion of natural products in the diet $^{13}$, uric acid supplementation ${ }^{10}$, vitamin $\mathrm{K}^{20}$ benefits, intake of salmon proteoglycans and soy protease ${ }^{18}$, calorie restrictions for disease activity control ${ }^{24}$, coffee intake for MS risk and progression ${ }^{49}$, excessive iron deposition as a pro oxidative and MS risk factor in diagnosed patients ${ }^{50}$ and dietary inflammatory index as a determinant of disease development ${ }^{51}$.

\section{DISCUSSION}

This integrative review analyzed the profile of articles on the relationship between nutrition, MS etiology and progression. The sample sizes of the studies evaluated were relatively small, which could be the result of the complexity of methodological procedures, as it is not possible to approach a large number of volunteers due to the difficulty of having access to MS-diagnosed patients.

We noticed that the use of vitamin D supplements is common among people who suffer from this condition ${ }^{3,52}$, with a significant number of individuals claiming to have received a doctor recommendation in this sense ${ }^{13}$. We also note that there is much evidence that use of vitamin D supplements reduces MS risks and improves clinical results of those who have been diagnosed with the disease or with Clinically Isolated Syndrome ${ }^{10,16-21,31,35,39,43,53-59}$. However, it is also common for researchers to suggest that more observational studies and mainly, more randomized clinical trials, should be performed seeking to provide definitive evidence on whom, how, when and how much supplements should be administered for primary and secondary prevention and treatment ${ }^{10,20,43,58}$. There is also no consensus on the ideal supplementation form and which serum levels should be targeted.

With regards to oils and fats, studies in animals or in vitro tests have predominantly evidenced that hypolipidemic ${ }^{14,24,60}$ diets or those diets that replace saturated by polyunsaturated fat ${ }^{18,21,61}$, in particular $\omega-3^{15,19,43,62}$, may exert a neuroprotective effect. Among the several suggested mechanisms, we should mention the strengthening of the blood-brain barrier, which avoids immune cell and neurotoxin access to the CNS and the reduction of pro-inflammatory cytokine synthesis. Fish oil was the most common $\omega-3$ supplementation of choice but studies that used hemp seed and primrose oils resulted in an improvement in fatty acid levels of erythrocyte membranes in MS patients ${ }^{28,30}$. Only one study suggested that long-chain fatty acids might exacerbate the disease ${ }^{63}$.

Small-scale clinical trials also proved that $\omega-3$ supplements reduced attack severity and duration but did not affect disability progress ${ }^{10}$. Hypolipidemic diets and $\omega-3$ supplementation-based diets were tested in humans and showed a reduction in episode rates, fatigue and cognitive functions. Research limitations with regards to the control of confounding variables do not permit definitive conclusions ${ }^{24}$.

As for antioxidant vitamins and natural bioactive compounds, the focus was on catechins, such as epigallocatechin-3-gallate polyphenols (ECGC) found in green tea ${ }^{22,64}$, quercetin, luteolin, fisetin ${ }^{65}$, hesperidin ${ }^{65,66}$, resveratrol, turmeric, curcumin ${ }^{10}$, tyrosol, hydroxytyrosol, daidzein, genistein, carotenoids (such as lycopene) as well as other antioxidant compounds such as saffron ${ }^{15}$ and ginkgo biloba ${ }^{10}$.

The use of supplements and vitamins proved to be common among MS patients and, although less frequent, there was also common use of special diets such as the Paleolithic and hypolipidemic diets like the Swank diet, which are poor in vitamins $\mathrm{A}, \mathrm{C}$ and $\mathrm{E}$, which may worsen MS prognosis ${ }^{13}$.

Vitamin A and its predecessors proved to be essential for immune system integrity. In the form of trans-retinoic acid or retinyl palmitate, the nutrient regulates the transition of unexpressive disease genes ${ }^{12,18,19}$ such as the FoxP9,17, which helps in the proliferation of regulatory-T cells (Treg) and attenuates $T$ helper 1 type ones. Tregs produce the secretion of TGF- $\beta$, which suppress the production of pro inflammatory cytokines (such as the IFN- $\gamma$ ) ${ }^{9,11}$. Vitamin $\mathrm{E}$, in the form of tocopherol in animal models, led to the regeneration of oligodendrocytes and the myelin sheath. In animals, vitamin $\mathrm{C}$, due to its protective role against oxidative damage, was effective in preventing experimental autoimmune encephalomyelitis (EAE), in which has a physiopathology partially similar to human $\mathrm{MS}^{18}$.

Taking into account these properties, special attention must be given to its consumption by $\mathrm{MS}^{14}$ patients, mainly when considering that these antioxidants are reduced in blood serum during attacks ${ }^{20}$.

We perceived a predominance of vitamin A experimental or human-related studies, however studies were heterogeneous in evaluated dosage and clinical practices, which makes it 
difficult to reach an ideal prescription.

As for natural bioactive compounds, literature suggests that flavonoids have some potential for limiting demyelination, reducing neuroinflammation and diminishing the exacerbated immune function ${ }^{65}$. In animals, for example, saffron ${ }^{15}$ and curcuma softened EAE symptoms by preventing oxidative stress and CNS invasion by lymphocytes. Hesperidin, a citrus flavonoid, exerted an immunological and histological effect on the $\mathrm{CNS}^{66}$. As an effective clinical result for flavonoids, in general, an improvement in the cognitive decline is mentioned, as well as a reduction in muscular weakness and fatigue (green tea ECGC) ${ }^{22}$ and attacks (ginkgo biloba) ${ }^{10}$. No clinical trials with curcuma as a modifying disease progression agent were found.

When analyzing research on dietary models, we corroborated that diet may exert a role in MS etiology and progression, as suggested by the disease risk growth in populations that consume excessive amounts of meat and dairy products, as well as it may affect the condition activity as shown by magnetic resonance image ${ }^{24}$.

Several studies that included different dietary standards were carried out but they are limited in terms of extrapolating results considering the small sample size, the short followup period and the presence of biases. Some findings from these works are shown below.

The lacto-vegetarian diet for example, as a common early childhood diet, is significantly more common among MS patients ${ }^{31}$. As a part of a plan focused on dietary and lifestyle change, it brings cognitive, emotional and physical benefits ${ }^{32}$. With regards to Western-style diets, it was identified a potential for deviating human cell metabolism towards biosynthetic paths ${ }^{25}$, including those of pro inflammatory molecules, which induce a low-degree chronic inflammation ${ }^{25,27}$. Besides this, intestinal dysbiosis and the consequent autoimmune stimulus are related to the Western $\operatorname{diet}^{25}$.

Dietary models that are part of the alternative medicine scope were also studied. Therefore, hot nature diet (in the view of Indian and Chinese medicine) supplemented with hemp seed and primrose oils reduced disability degree as measured by the Expanded Disability Status Scale (EDSS), and the fatty acid composition of the erythrocyte membrane, a severity reduction predictor $28,29,30$.

An anti-inflammatory dietary standard basically composed of fruits, vegetables, legumes, beans and many $\omega-3$ sources tended to improve quality of life, physical, cognitive and functional capacity of people with Relapsing-Remitting Multiple Sclerosis (RRMS) ${ }^{26}$.

The Mediterranean diet was recommended in one study due to its anti-inflammatory properties, provided gluten is excluded ${ }^{24,25}$.

The Paleolithic diet was also analyzed and despite being considered as very limited in micronutrients ${ }^{13}$, it resulted in a reduction of fatigue, improvement in physical and mental capacity and upper and lower limbs strength ${ }^{23}$.

In short, it was perceived that there is a need for further and larger blinded clinical trials with long-term follow-up that can assess the role of healthy diets on each MS type. However, in general terms, it can be said that a healthy diet low in saturated fat, salt and sugar is beneficial in the presence of MS.

With respect to the consumption of fiber and probiotics, in vitro and animal studies showed conflicting results and, in some cases, even suggested symptom exarcebation ${ }^{10}$. When favorable, research suggests that probiotics may contribute to a healthy enteric microflora that can stimulate dendritic intestinal cells to produce interleukin-10 and help in the proliferation of Treg cells that regulate the autoimmune system and the infiltration of lymphocytes in the bone marrow $^{10,18,67}$. Intake of probiotic capsules for 12 weeks by MS patients had favorable effects on EDSS, mental health markers, inflammatory and insulin-resistance parameters, $\mathrm{HDL}$, total/HDL cholesterol ratio and malondialdehyde levels, an oxidative stress marker ${ }^{68}$.

The possibility of reaching a consensus on the ideal probiotic strain is remote but Lactobacillus casei was the most commonly mentioned in literature ${ }^{10,18}$. MS treatment was proposed as a bias for a small-scale study with humans (clinical trial), due to an alteration of bacteria populations provoked by glatiramer acetate and vitamin $\mathrm{D}^{68}$ supplementation.

In any case, benefits are also found if instead of a probiotic supplementation, substrates for a normal intestinal flora are provided ${ }^{39,69}$. In humans, vegetable-based diets were associated to a larger intestinal colonization by beneficial bacteria $^{24,69}$ such as Faecalibacterium and Eubacteria rectale, which produce short-chain fatty acids that induce Treg cell differentiation ${ }^{69}$.

As for the influence of body composition, obesity before or during adolescence seems to contribute to a higher MS risk $^{24}$. One of the hypothesis is that a higher BMI may intensify the proliferation of T helper 17 cells $^{34}$ or that it may be linked to a lower intestinal bacteria diversity ${ }^{24}$. Besides, adiposity assessed by $\mathrm{BMI}$ or the body composition may be directly or indirectly intermediated by insulin resistence ${ }^{24,34}$, thus exacerbating oxidative stress and inflammatory cytokine production, which may induce not just the development of MS but also an exacerbation of symptoms ${ }^{36}$. Therefore, deterioration in physical and mental health may happen due to any ponderal excess level according to $\mathrm{BMI}^{37}$.

A single case-control study suggested no relationship between obesity and MS by identifying that BMI did not differ between people with or without the disease ${ }^{33}$.

It was noticed that there is not sufficient evidence to affirm that MS individuals are more overweight and that MS patients may be under higher cardiovascular risk with regards to their body adiposity ${ }^{3}$, compared to persons without MS.

Studies that analyzed the effects of vitamin B complex showed that in vivo and in vitro, cobalamin positively affected the demyelination process ${ }^{18,21}$. Folate also has its relevance for humans, as its deficiency increases homocysteine serum levels, which is a cytotoxic amino acid for neural 
cells that may also contribute to fatigue ${ }^{39}$. Although this benefit is known, we noticed that the use of special folic acid-deficiency diets is common among MS people, as it is the case of the Paleolithic and hypolipidemic diets ${ }^{13}$.

Studies with antioxidant minerals evidenced the presence of selenium serum levels significantly lower among EMRR, mainly due to a nutritionally poor diet ${ }^{40}$, which means a lower antioxidant defense capacity $\mathrm{y}^{18,40}$ and as a consequence, a higher disease progression risk. In animals, the inclusion of a selenium-rich diet protects neurological manifestations of EAE (similar to MS) and reduces spinal cord lymphocyte infiltration ${ }^{18}$.

Zinc may also offer advantages and its supplementation in animals enables the reduction of T helper cell 1 and $T$ helper 17 cell proliferation, as well as diminishing attack rate. In humans, its proportion with regards to copper (copper/ zinc ratio) in a single study was proposed as a marker for oxidative stress and bad prognosis indicator for emotional alterations, being necessary to develop further research on the subject ${ }^{41}$. Although low consumption levels were verified among MS patients, the relationship of zinc with fatigue incidence was not confirmed ${ }^{39}$.

Magnesium was not widely studied in research but in MS individuals, its deficiency increased fatigue-related scores ${ }^{39}$.

As previously stated, some nutritional factors were specifically studied during the last five years. However, it is important to highlight the main findings, which shall be corroborated or rejected with the development of future research following the same guidelines.

It was verified that professional support aimed at developing self-care and self-efficiency capabilities may contribute to the adoption of healthy nutritional patterns among MS adult patients $\mathrm{s}^{42,44,45}$.

With regards to the benefits of food groups intake, it was found that moderate alcohol intake and fish intake three or more times a week is associated with lower fatigue incidence ${ }^{43}$.

Moderate tryptophan intake ( 0.03 to $0.04 \mathrm{~g} / \mathrm{Kg}$ per meal) associated to whey protein supplementation resulted in better learning skills and memory performance in MS patients ${ }^{46}$.

A study on salt effects concluded that well controlled large-scale research remains necessary in order to provide substantial evidence on the pathophysiological mechanisms involved between excessive salt intake and the exacerbation of immune responses ${ }^{47}$. There is also a scarcity of clinical trials that can prove if intake reduction related to immunomodulatory therapies may interfere in the disease activity ${ }^{47}$. Based on current information available in pediatrics, excessive sodium chloride intake did not proved to be significantly linked to MS risk ${ }^{48}$.

Consumption of natural products seems to be common among MS sufferers (44.4\%), however no research that studied the relationship between this nutritional pattern and MS prognosis was found ${ }^{13}$.

Uric acid supplementation in animals reduced CNS invasion by immune cells and blocked cell apoptosis by free radicals. This resulted in an EAE prevention and a reduction in the disease progress. In humans, a large study performed in medical databases showed that MS and Gout are reciprocally exclusive conditions, which leads to conclude that hyperuricemia protects against MS. Uric acid serum levels also seem to decrease during episodes and increase in EMRR patients after treatment with diseasemodifier drugs is initiated. Therefore, such supplementation seems promising ${ }^{10}$.

With regards to vitamin $\mathrm{K}$, it is believed that oligodendrocyte and immature neuron precursors are protected from oxidative injury when vitamin K2 (menaquinone) is offered. However, only one study in animals suggested a positive effect and the evidence of a benefit for humans is still too weak to provide any recommendations ${ }^{20}$.

Favorable results however were found in rats with $\mathrm{EAE}$ that were submitted to oral intake of salmon proteoglycans. Microbiota composition of the small intestine improved and clinical and histological manifestations of the disease were mitigated. Results were associated to the suppression of interferon and IL 17 production. A soy-derivative protease inhibitor denominated Bowman-Birk seems to have antiinflammatory potential and, in rats, also mitigated EAE clinical signs, reducing CNS inflammation and optic neuritis. Soy phytoestrogens such as genistein, daidzein and coumestrol may also partially contribute to these effects due to their anti-inflammatory properties, such as the reduction in nitric oxide synthesis and pro inflammatory and microglial activation cytokines ${ }^{18}$.

Calorie restrictions proved to be effective in reducing post-prandial inflammation, thus affecting disease activity control ${ }^{24}$.

With regards to coffee intake, it was perceived that based on a review study, throughout the years, many case-control studies were developed seeking to identify an association between coffee intake and MS. Results are conflicting but in those with favorable results, we observed an inverse association with MS risk. However, there was also interference with the condition progression, as people with MS attack who consumed coffee on a daily basis took five years to reach an EDSS of six compared to those who did not drink coffee ${ }^{49}$.

One review suggested that abnormal accumulation of iron may cause neurodegeneration by inducing lipid peroxidation and CNS cell death. Excessive iron deposition, confirmed by magnetic resonance sequences, was associated with unfavorable clinical manifestations in MS individuals. It is necessary to elucidate if iron deposition is a marker or a mediator of the MS degenerative cascade, as well as physiopathologic mechanisms involved in this relation. Consequently, many gaps still exist and the efficacy of antioxidant and iron chelators is still questionable ${ }^{50}$.

Finally, a single case-control study ${ }^{51}$ investigated the potential of the dietary inflammatory index to predict MS risk and showed that individuals with a more pro inflammatory diet had a higher risk of developing the disease. 


\section{CONCLUSIONS}

In conclusion, this integrative review showed that, with the exception of multicenter studies, most research on the relationship between MS development and nutrition still involves small samples. Oftentimes authors point at this factor as a limiting issue.

It was also noticed that in almost all nutritional patterns studied, authors suggested the need for further observational studies and clinical trials in humans. With the available data, however, it is possible to affirm that a healthy diet contributes to both the prevention and mitigation of disease progression. However, it is not yet possible to make the same affirmation with regards to dietary supplements.

Although publications specify the need to develop randomized clinical trials with long-term follow-up that can assess the role of diet in the health condition of MS patients, there is still a scarcity of cross-sectional and casecontrol type studies. Considering the many knowledge gaps that make it impossible to reach a consensus on an ideal nutritional pattern, both types of study designs are needed.

\section{REFERENCES}

1. Ortiz GG, Pacheco-Moisés FP, Bizer-Quintero OK, RamírezAnguiano AC, Flores-Alvarado LJ, Ramírez-Ramírez V, et al. Immunology and oxidative stress in multiple sclerosis: clinical and basic approach. Clin Dev Immunol. 2013; 2013: 1-14.

2. Kakalacheva K, Lunemann JD. Environmental triggers of multiple sclerosis. FEBS Letters. 2011; 585: 3724-29.

3. Multiple Sclerosis International Federation. Atlas of MS 2013: mapping multiple sclerosis around the world. London: Summers Editorial; 2013. 28p.

4. Jones CA, Pohar SL, Warren S, Turpin KVL, Warren KG. The burden of multiple sclerosis: a community health survey. Health Qual Life Outcomes [Internet]. 2008 Jan 7; 6(1) [cited 2014 Jun 16]. Available from: http://www.hqlo.com/content /6/1/1. Referenced in doi 10.1186/1477-7525-6-1

5. Farinotti $M$, Vacchi L, Simi S, Di Petrantonj C, Brait L, Fillipini G. Dietary interventions for multiple sclerosis (review). Cochrane Database Syst Rev. 2012; 2012(12) [cited 2014 Apr 14]. Available from: https://www.ncbi.nlm.nih. gov/ pubmed/232356053. Doi: 10.1002/14651858.CD004192. pub3

6. Peláez RB, Casas NV. Role of nutrition in prevention and course of neurodegenerative diseases. Nutrición Hospitalaria. 2009; 2(2): 13-25.

7. Brazil. Ministry of Health. Drug Department CEAF. Health Portal [Internet]. 2017 mar. [cited 2017 jul 5]. Available from: http://portalarquivos.saude.gov.br/images/ pdf/2017/ Março/20/Tabela-de-Situacoes-Clinicas-marco-2017.pdf.

8. Brazil. Ministry of Education. CAPES/MEC Portal journal collection. CAPES Portal Journals [Internet]. 2016 jan. [cited 2016 Jan 31]. Available from: http://www-periodicos-capesgov.br.ez76.periodicos.capes.gov.br/index.php?option =com_pcollection\&ltem id=104. Accessed on: 31 jan. 2016.

9. Dorosty-Motlagh AR, Honarvar NM, Sedighiyan M, Abdolah $M$. The molecular mechanisms of a deficiency in multiple sclerosis. I Mol Neurosci. 2016; 60(1): 82-89.

10. Geldern G, Mowry EM. The influence of nutritional factors on the prognosis of multiple sclerosis. Nat Rev Neurol. 2012; 8(12): 678-689.
11. Honarvar NM, Harirchian MH, Koohdani F, Siassi F, Abdolahi M, Bitarafan S, Salehi E, Safraian MA, Eshraghian MR, SaboorYarghiAA. The effect of vitamin a supplementation on retinoic acid-related orphan receptor $\gamma t$ (ROR $\gamma t$ ) and interleukin-17 (IL-17) gene expression in avonex-treated multiple sclerotic patients. J Mol Neurosci. 2013; 51(3): 749-753.

12. Loken-Amsrud KI. Retinol levels are associated with magnetic resonance imaging outcomes in multiple sclerosis. Mult Scler J. $2013 ;$ 19(4): 451-457.

13. Masullo L, Papps MA, Contugna N, Baker S, Mahoney L, Trabulsi J. Complementary and alternative medicine use and nutrient intake among individuals with multiple sclerosis in the United States. J Comm Health. 2015; 40(1):153-60. Doi: 10.1007/s10900-014-9913-z

14. Mauriz E, Laliena A, Vallejo D, Tuñón $M$, Rodríguez-López $J M$, Rodríguez-Pérez R, García-Fernández MC. Effects of a low-fat diet with antioxidant supplementation on biochemical markers of multiple sclerosis long-term care residents. Nutr Hosp. 2013; 28(6): 2229-2235.

15. Nieto P, Serrano-Díaz J, Murcia MA, Carmona M, Alonso G, Martinez-Tome M. Role of antioxidants in the treatments of multiple sclerosis. Ann Nutr Metab. 2013; 63(Supp/1): 1960.

16. Polachini CRM, Spanevello RM, Zanini D, Baldissarelli J, Pereira LB, Schetinger MRC, Cruz IBM, Assmann CE, Bagatini MD, Morsch VM. Evaluation of delta-aminolevulinic dehydratase activity, oxidative stress biomarkers, and vitamin d levels in patients with multiple sclerosis. Neurotox Res. 2016; 29(2): 230-42.

17. Saboor-Yaraghi AA, Harirchian MH, Mohammadzadeh HN, Bitarafan S, Abdolahi M, Siassi F, Salehi E, Sahraian MA, Eshraghian MR, Roostaei $T$, Koohdani $F$. The effect of vitamin A supplementation on Foxp3 and TGF-B gene expression in avonex-treated multiple sclerosis patients. J Mol Neurosci. 2015; 56(3): 608-612.

18. Schmitz K, Barthelmes J, Stolz L, Beyer S, Diehl O, Tegeder I. "Disease modifying nutricals" for multiple sclerosis. Pharm Ther. 2015; 148 (9): 85-113.

19. Shiri-shahsavar MR, Mirshafiee A, Parastouei K, Ebrahimi-Kalan A, Yekaninejad S, Soleymani F, Chahardoli R, Mazaheri NFR, Saboor-Yaraghi AA. A novel combination of docosahexaenoic acid, all-trans retinoic acid, and 1, 25-dihydroxyvitamin D.sub.3 reduces T-bet gene expression, serum interferon gamma, and clinical scores but promotes PPARI[superscript three] gene expression in experimental autoimmune. J Mol Neurosci. 2016; 60(4): 498-509.

20. Torkildsen $\varnothing$, Løken-Amsrud KI, Wergeland S, Myhr KM, Holmøy T. Fat-soluble vitamins as disease modulators in multiple sclerosis. Acta Neurol Scand. 2013; 127(Suppl 196): 16-23.

21. Adamo AM. Nutritional factors and aging in demyelinating diseases. Genes Nutr. 2014; 9(1): 360-368.

22. Mahler A, Steiniger J, Bock M, Klug L, Parreidt N, Lorenz $M$, et al. Metabolic response to epigallocatechin-3-gallate in relapsing-remitting multiple sclerosis: a randomized clinical trial. Am J Clin Nutr. 2015; 101(3): 487-495.

23. Irish AK. Evaluation of a modified paleolithic dietary intervention for the treatment of relapsing remitting multiple sclerosis [dissertation]. lowa: lowa University; 2015.

24. Altowaijri G, Fryman A, Yadav V. Dietary interventions and multiple sclerosis. Curr Neurol Neurosci Rep [Internet]. 2017 Mar; 17(3) [cited 2017 Jun 6]. Available from: https://link. springer.com/article/10.1007\%2Fs11910-017-0732-3. Doi 10. 1007/s11910-017-0732-3 
25. Riccio $P$, Rossano R. Nutrition facts in multiple sclerosis. ASN Neuro. 2015; 7(1):1-20. doi: 10.1177/1759091414568185

26. Bennett SE, Bromley L. Impact of nutrition on quality of life, fatigue and functional mobility in ms: a case series analysis. In: Proceedings of the 20th Annual Conference on Rehabilitation in Multiple Sclerosis; Milan: EURIMS; 2015.

27. Jörg S, Grohme DA, Erzler M, Binsfeld M, Haghikia A, Müller $D N$, Linker RA, Kleinewietfeld M. Environmental factors in autoimmune diseases and their role in multiple sclerosis. Cell Mol Life Sci. 2016; 73(24): 4611-4622.

28. Rezapour-Firouzi S, Arefhosseini SR, Ebrahimi-Mamaghani $M$, Farhoudi M, Baradaran B, Ali TM, et al. Erythrocyte membrane fatty acids in multiple sclerosis patients and hotnature dietary intervention with co-supplemented hemp-seed and evening-primrose oils. Afr I Tradit Complement Altern Med. 2013; 10(6): 519-27.

29. Rezapour-Firouzi S, Arefhosseini SR, Mehdi F, Mehrangiz EM, Baradaran B, Sadeghihokmabad E, et al. Immunomodulatory and therapeutic effects of hot-nature diet and co-supplemented hemp seed, evening primrose oils intervention in multiple sclerosis patients. Complement Ther Med. 2013; 21(5): 47380.

30. Rezapour-Firouz S, Arefhosseini SR, Ebrahimi-Mamaghani M, Baradaran B, Sadeghihokmabad E, Torbati M, et al. Activity of liver enzymes in multiple sclerosis patients with hot-nature diet and co-supplemented hemp seed, evening primrose oils intervention. Complement Ther Med. 2014; 22(6): 986-93.

31. Malli C, Pandit L, D'Cunha A, Mustafa S. Environmental factors related to multiple sclerosis in Indian population. Plos One [Internet]. 2015 Apr; 10(4) [cited 2016 Nov 18]. Available from: http://journals.plos.org/plosone/article/ file?id=10.1371/ journal. pone.0124064\&type=printable. 0135221.pdf.

32. Null G, Pennesi L, Feldman M. Nutrition and lifestyle intervention on mood and neurological disorders. I Evid Based Complementary Altern Med. 2017; 22(1) 68-74.

33. Coe S, Onia Bl, Collettb J, Clegga M, Dawesb H. Increased carbohydrate and energy consumption in people with multiple sclerosis compared to healthy controls. Proc Nutr Soc. 2015; 74(1): 115.

34. Endo Y, Yokote $K$, Nakayama T. The obesity-related pathology and Th17 cells. Cell Mol Life Sci. 2017; 74: 1234-1245.

35. Hagan KA, Munger KL, Ascherio A, Grodstein F. Epidemiology of major neurodegenerative diseases in women: contribution of the Nurses' Health study. Am J Public Heath. 2016; 106(9): 1650-5. doi: 10.2105/AJPH.2016.303324

36. Jelinek GA, De Livera AM, Marck CH, Brown CR, Neate SL, Taylor KL, Weiland TJ. Associations of lifestyle, medication and socio-demographic factors with disability in people with multiple sclerosis: an international cross-sectional study. Plos One [Internet]. 2016 ago; 11(8) doi 10.1371/journal. pone.0161701

37. Oliveira $S R$, Simão ANC, Kallaur AP, de Almeida ER, Morimoto HK, Lopes J, Dichi I, Kaimen-Maciel DR, Reiche EM. Disability in patients with multiple sclerosis: influence of insulin resistance, adiposity, and oxidative stress. Nutr. 2014; 30(3):268-73. doi: 10.1016/j.nut.2013.08.001

38. Wens I, Dalgas U, Stenager E, Eijnde BO. Risk factors related to cardiovascular diseases and the metabolic syndrome in multiple sclerosis: a systematic review. Mult Scler. 2013; 19(12): 1556-1564.

39. Bitarafan $S$, Harirchian $M$, Nafissi S, Sahraian $M$, Togha $M$, Siassi F, Saedisomeolia A, Alipour E, Mohammadpour $N$, Chamary M, Honarvar NM, Saboor-Yaraghi A. Dietary intake of nutrients and its correlation with fatigue in multiple sclerosis patients. Iran I Neurol. 2014; 13(1): 28-32.

40. Socha K, Kochanowicz J, Karpińska E, Soroczyńska J, Jakoniuk M, Mariak Z, Borawska MH. Dietary habits and selenium, glutathione peroxidase and total antioxidant status in the serum of patients with relapsing-remitting multiple sclerosis. Nutr J. 2014 Jun; 18; 13: 62. Doi: 10.1186/1475-2891-13-62

41. Socha K, Karpińska E, Kochanowicz J, Soroczyńska J, Jakoniuk M, Wilkiel M, Mariak Z, Borawska MH. Dietary habits, concentration of copper, zinc, and $\mathrm{Cu}$-to-Zn ratio in serum and ability status of patients with relapsing-remitting multiple sclerosis. Nutr. 2017 jul/aug; 39/40(62): 76-81.

42. Plow M, Finlayson M, Cho C. Correlates of nutritional behavior in individuals with multiple sclerosis. Disabil Health J. 2012; 5(4): 284-291.

43. Weiland TJ, Jelinek GA, Marck CH, Hadgkiss EJ, Meer DM, Pereira NG, et al. Clinically significant fatigue: prevalence and associated factors in an international sample of adults with multiple sclerosis recruited via the internet. Plos One. 2015 feb; 10(2). Doi: 10.1371/journal.pone.0115541

44. Plow M, Golding M. A qualitative study of multiple heat/h behaviors in adults with multiple sclerosis. Int J MS Care. 2016; 18(5): 248-256.

45. Riemann-Lorenz K, Eilers M, Von Geldern G, Schulz KH, Köpke S, Heesen C. Dietary interventions in multiple sclerosis: development and pilot-testing of an evidence based patient education program. Plos One. 2016 oct; 11(10). doi 10.1371/ journal.pone.0165246

46. Lieben CK, Blokland A, Deutz NE, Jansen W, Han G, Hupperts RM. Intake of tryptophan-enriched whey protein acutely enhances recall of positive loaded words in patients with multiple sclerosis. Clin Nutr. 2017 Jan; 5(2). Doi: 10.1016/j. clnu.2016.12.029

47. Hucke S, Wiendl H, Klotz L. Implications of dietary salt intake for multiple sclerosis pathogenesis. Mult Scler J. 2016; 22(2): 133-139.

48. McDonald J, Graves J, Waldman A, Lotze T, Schreiner T, Belman A, Greenberg B, Weinstoch-Guttman B, Aaen G, Tillema JM, Hart J, Lulu S, Ness J, Harris Y, Rubin J, Candee $M$, Krupp LB, Gorman $M$, Benson L, Rodrifuez $M$, Chitnis $T$, Mar S, Barcellos LF, Laraia B, Rose J, Roalstad S, Simmons T, Casper TC, Waubant E. A case-control study of dietary salt intake in pediatric-onset multiple sclerosis. Mult Scler Relat Disord. 2016 Mar; 87(6) doi: 10.1016/j.msard.2016.02.011

49. Sharif K, Watad A, Bragazzi NL, Adawi M, Amital H, Shoenfeld $Y$, et al. Coffee and autoimmunity: More than a mere hot beverage. Autoimmun Rev. 2017 may. Doi 10.1016/j. autrev.2017.05.007

50. Stankiewicz J, Neema M, Ceccarelli A. Iron and multiple sclerosis. Neurobiol Aging. 2014; 35 (Suppl 2): 51-58.

51. Shivappa N, Hebert JR, Behrooz M, Rashidkhani B. Dietary inflammatory index and risk of multiple sclerosis in a casecontrol study from Iran. Neuroepidemiol. 2016; 47: 26-31.

52. Jelinek GA, De Livera AM, Marck CH, Brown CR, Neate $S L$, Taylor KL, Weiland TJ. Lifestyle, medication and sociodemographic determinants of mental and physical healthrelated quality of life in people with multiple sclerosis. BMC Neurology. 2016 Nov; 16(235). Doi: 10.1186/s12883-0160763-4

53. Ascherio A, Munger KL, Lünemann JD. The initiation and prevention of multiple sclerosis. Nat Rev Neurol. 2012; 8(11): 602-612.

54. Bhargava P, Steele SU, Waubant E, Revirajan NR, Marcus J, 
Dembele M, Cassard SD, Hollis BW, Crainiceanu C, Mowry EM. Multiple sclerosis patients have a diminished serologic response to vitamin D supplementation compared to healthy controls. Mult Scler. 2016; 22(6): 753-760.

55. Cantorna MT, Zhao J, Yang L. Vitamin D, invariant natural killer T-cells and experimental autoimmune diseases. Proc Nutr Soc. 2012; 71(1): 62-66.

56. Hewison M. Vitamin D and immune function: an overview. Proc Nutr Soc. 2012; 71(1): 50-61.

57. Koriem KMM. Multiple sclerosis: new insights and trends. Asian Pac J Trop Biomed. 2016; 6(5): 429-440.

58. Peterlik M. Vitamin D insufficiency and chronic diseases: hype and reality. Food Funct. 2012; 3(8): 784-794.

59. Romero F, Martínez JJA, López VL, Martín IG, Working Group on Calcium and Vitamin D in Enteral Nutrition. Enteral nutrition in neurological patients; is there enough vitamin D content in commonly used formulas? Nutr Hosp. 2012; 27(2): 341-348.

60. Timmermans $S$, Bogie $J F$, Vanmierlo $T$, Lütjohann $D$, Stinissen P, Hellings N, Hendriks JJ. High fat diet exacerbates neuroinflammation in an animal model of multiple sclerosis by activation of the renin angiotensin system. I Neuroimmun Pharmacol. 2014; 9(2): 209-17.

61. Pantzaris MC, Loukaides GN, Ntzani EE, Patrikios IS. A novel oral nutraceutical formula of omega-3 and omega- 6 fatty acids with vitamins (PLP10) in relapsing remitting multiple sclerosis: A randomised, double-blind, placebo-controlled proof-of-concept clinical trial. BMJ Open. 2013 Apr; 3(4) doi 10.1136/bmjopen-2012-002170

62. Hoare S, Lithander F, Van der Mei I, Ponsonby AL, Lucas R, Ausimmune Investigator Group. Higher intake of omega-3 polynsaturated fatty acids is associated with a decreased risk of a first clinical diagnosis of central nervous system demyelination: results from the Ausimmune study. Mult Scler. 2016; 22(7): 884-892.

63. Haghikia A, Jörg S, Duscha A, Berg J, Manzel A, Waschbisch A, Hammer A, Lee DH, May C, Wilck N, Balogh A, Ostermann Al, Schebb NH, Akkad D, Grohme DA, Kleinwietfeld $M$, Kempa S, Thöne J, Demir S, Müller DN, Gold R, Linker RA. Dietary fatty acids directly impact central nervous system autoimmunity via the small intestine. Immunity. 2015; 43(4): 817-829.

64. Wu D, Wang J, Pae M, Meydani SN. Green tea EGCG, $T$ cells, and T cell-mediated autoimmune diseases. Mol Aspects Medicine. 2012; 33(1): 107-118.

65. Solanki I, Parihar P, Mansuri ML, Parihar MS. Flavonoid-based therapies in the early management of neurodegenerative diseases. Adv Nutr. 2015; 6(1): 64-72.

66. Ciftci O, Ozcan C, Kamisli O, Cetin A, Basak N, Aytac B. Hesperidin, a citrus flavonoid, has the ameliorative effects against experimental autoimmune encephalomyelitis (EAE) in a C57BL/J6 mouse model. Neurochem Res. 2015; 40(6): 1111-1120.

67. Glenn JD, Mowry EM. Emerging concepts on the gut microbiome and multiple sclerosis. Journal Interferon Cytokine Res. 2016; 36(6): 347-357.

68. Kouchaki E, Tamtaji OR, Salami M, Bahmani F, Daneshvar $K R$, Akbari E, Tajabadi-Ebrahimi M, Jafari P, Asemi Z. Clinical and metabolic response to probiotic supplementation in patients with multiple sclerosis: a randomized, double-blind, placebo-controlled trial. Clin Nutr. 2016; 36(5): 1245-1249.

69. Croxford JL, Miyak S. Immunoregulation of multiple sclerosis by gut environmental factors. Clin Exp Neuroimmunol. 2015; 6(4): 362-369. 